\title{
Sludge Density Prediction in a Wastewater Chemical Coagulation Process
}

\author{
Margarita Teutli-León ${ }^{1}$, María Elena Pérez-López² \\ ${ }^{1}$ Engineering Department, Autonomous University of Puebla (BUAP), Puebla, Mexico \\ ${ }^{2}$ Interdisciplinary Research Center for the Local Integral Research, National Polytechnical Institute at Durango \\ (IPN-CIIDIR-DGO), Durango, Mexico \\ Email: teutli23@hotmail.com,maelena0359@yahoo.com,
}

Received April 25, 2013; revised May 27, 2013; accepted June 30, 2013

Copyright (C) 2013 Margarita Teutli-León, María Elena Pérez-López. This is an open access article distributed under the Creative Commons Attribution License, which permits unrestricted use, distribution, and reproduction in any medium, provided the original work is properly cited.

\begin{abstract}
This paper reports an approach to estimate the sludge density in a physicochemical treatment of municipal wastewater, experiments considered 4 coagulants (aluminum sulfate SAl, iron sulfate SFe, aluminum polychloride PAX, iron polychloride PIX), and 2 flocculant products (cationic CP and anionic AP polymers). Experimental approach is based on running a set of jar tests at different coagulant concentrations. After the stirring and resting times took place, $\mathrm{pH}$ and conductivity were registered finding that SAl and SFe either with or without polymers are the coagulants producing the higher $\mathrm{pH}$ drop. Conductivity measures also establish two kind of data since higher conductivity $\left(\right.$ about $\left.2000 \mu \mathrm{S} \cdot \mathrm{cm}^{-1}\right)$ was observed for SAl, and PIX, PIX + CP, PIX + AP; otherwise a conductivity about $1300 \mu \mathrm{S} \cdot \mathrm{cm}^{-1}$ was observed for $\mathrm{SAl}+\mathrm{PC}, \mathrm{SFe}$ and PAX alone and with CP or AP. Settleable solids (SST) determined with an Imhoff cone were similar for sulfates and polychlorides, but dry sludge (DS) clearly set up two groups the one with higher sludge content corresponds to sulfates group. The quotient of DS divided by the SST provided an estimation of the apparent sludge density, in this way it was observed that higher densities were obtained for sludge from sulfates at lower coagulant concentrations; also sludge from SFe was heavier than the one from SAl. Otherwise, polychlorides produced a lighter sludge in respect to the one obtained with sulfates, and between them the PIX coagulant provided a heavier sludge than the PAX coagulant.
\end{abstract}

Keywords: Coagulant; Flocculant; Wastewater Treatment; Sludge Density

\section{Introduction}

Usually wastewater treatment plants (WWTP) are referred in three levels: primary, secondary and tertiary treatment. In Latin America, primary wastewater treatment has been implemented for several communities, but it has been observed that the organic load is high enough so additional steps are required in order to process the wastewater, applied alternatives are either a secondary treatment (biological) or the named Advanced Primary Treatment (APT), the last one is a physicochemical process which allows simultaneous precipitation of several contaminants, since simultaneously use both coagulant and flocculant for enhancing floc formation and settling. According to Vesilind [1] an estimation of associated elimination yields correspond to $60 \%-90 \%$ in settleable solids (SST), 25\% - 40\% in biochemical oxygen demand (BOD), 30\% - 60\% in chemical oxygen demand (COD), $70 \%-90 \%$ in phosphorus (P), and $80 \%-90 \%$ in pathogens.
Although an APT process use the same infrastructure than a primary treatment, the fact that municipal wastewater exhibit seasonal variations in its chemical composition leads to the need of running several jar tests in order to find the right reagent dosage, which so far define the amount of sludge produced and its handling procedures. Usually to increase phosphorus removal, the chemical requirements impact increasing $15 \%$ the amount of produced sludge since chemical addition may be in excess of stoichiometric requirements [2]. Another problem derived from chemical addition is that sludge dewatering becomes lowered by a raise in salinity, it has been proven that both organic polyelectrolytes and alum provide an improvement on dewaterability [3]. According to Kalderis [4] the most important factors in sludge management costs are: 1) physical and chemical characteristics; 2) quantity; 3) legal framework; 4) potential valorization and re-use; and 5) land availability and cost. Therefore, it is important that WWTP operators have the capacity to 
predict in a simple way the amount of sludge produced from simple routine procedures such as determining SST, and dry sludge.

This work is an approach to correlate SST and dry sludge amount in order to predict sludge density based on applied coagulant concentration.

\section{Methodology}

\subsection{Reagents}

Samples of municipal wastewater were obtained from a WWTP located at the southwest in the city of Puebla. This WWTP applies an APT process using aluminum sulfate as coagulant. By this reason aluminum sulfate is considered as one reagent. In jar tests applied chemical products comprise the coagulants: aluminum sulfate (SAl), iron sulfate ( $\mathrm{SFe}$ ), aluminum polychloride (PAX) and iron polychloride (PIX); also, applied flocculants were cationic and anionic polyacrylamide (CP, AP). All of these chemicals were commercial products provided by Kemira Company.

\subsection{Instruments}

The jar tests were run in a Kemwater flocculator using the following coagulant concentrations: $40,60,80,100$, 120, 140 part per million (ppm) of each coagulant SAl, SFe, PAX, PIX. Flocculants (CP, AP) were added in a dosage of $1 \mathrm{ppm}$. During experimentation a follow up of chemical parameters was done using portable meters CONDUCTRONIC brand for $\mathrm{pH}$ and conductivity; otherwise, color, turbidity, and COD were measured with the appropriate routine in a HACH DR 2500 spectrophotometer. Settleable solids (SST) were measured with an Imhoff cone, and sludge drying was done in a Shell Lab stove.

\section{Results and Discussion}

It is well known that $\mathrm{SAl}$ use produces a $\mathrm{pH}$ abatement then it is required to raise the $\mathrm{pH}$ before applying the coagulant. Experimental $\mathrm{pH}$ data show that $\mathrm{SAl}$ and $\mathrm{SFe}$ produced a $\mathrm{pH}$ drop of about one unit while the polychloride PAX and PIX drop $\mathrm{pH}$ in about 0.5 units.

Figure 1 presented results for the observed conductivity values for all coagulant and flocculant combinations. As it can be observed there are two groups one of high conductivity formed by SAl, PIX, PIX + CP, PIX + AP; and one of lower conductivity formed by the Sal $+\mathrm{CP}$, $\mathrm{SFe}, \mathrm{SFe}+\mathrm{CP}, \mathrm{SFe}+\mathrm{AP}, \mathrm{PAX}, \mathrm{PAX}+\mathrm{CP}, \mathrm{PAX}+\mathrm{AP}$. Determined settleable solids amount (SST) are presented in Figures $\mathbf{2}$ and 3. Figure 2 corresponds to sulfates with and without cationic polymer (CP). As it can be observed inclusion of the CP produces a drop in the amount of SST for SAl at all concentrations; otherwise, SFe is only

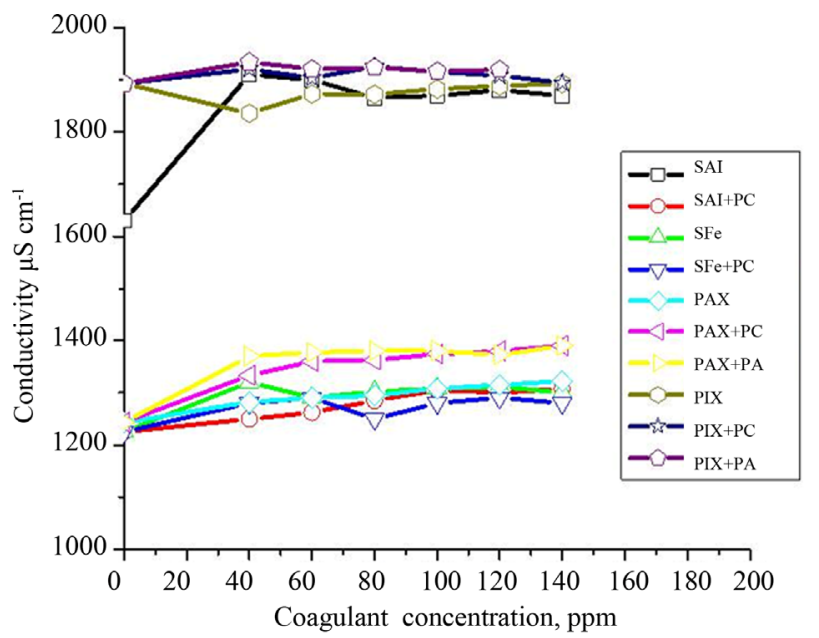

Figure 1. Conductivity results as function of coagulant concentration.

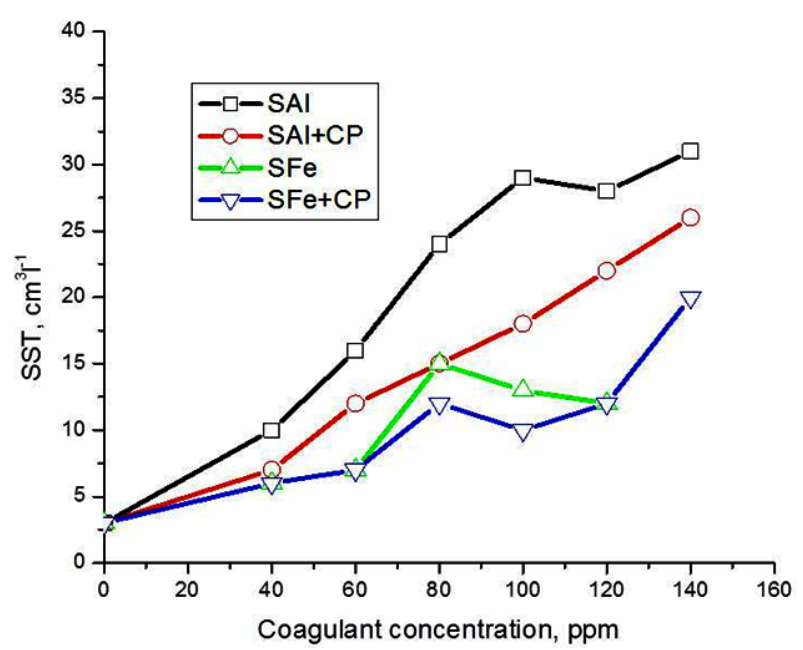

Figure 2. Settleable solids results for SAl and SFe as function of coagulant concentration.

slightly affected at 80 and 100 ppm having a lowering in SST, while all other concentrations provide the same amount of SST with or without CP.

Figure 3 presented obtained results for aluminum and iron polychlorides. As can be observed the PAX SST decrease with the addition of either CP or AP; while the PIX SST amount decrease slightly only with the AP at 80 and $120 \mathrm{ppm}$ coagulant concentration.

Figure 4 presented results for the amount of Dry Sludge (DS) obtained from each jar test, as it can be observed there are two groups the first belongs to the sulfates $\mathrm{SAl}$ and $\mathrm{SFe}$ in the range of 0.2 to $0.35 \mathrm{~g} \cdot \mathrm{l}^{-1}$, and the second one in the range of 0.02 to $0.12 \mathrm{~g} \cdot 1^{-1}$ corresponds to the polychlorides PAX and PIX, with and without polymers. Data for SAl exhibit an irregular point at $80 \mathrm{ppm}$ of coagulant, but once the $\mathrm{CP}$ is added values become more regular reducing the sludge amount to the range between 0.2 and $0.25 \mathrm{~g}^{-1}$, interval which is lower 


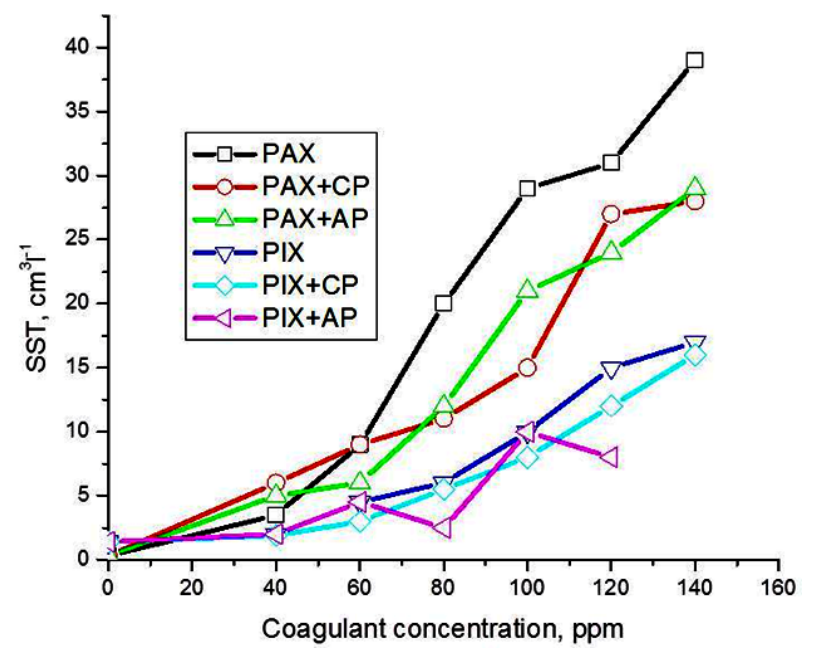

Figure 3. Settleable solids for PAX and PIX as function of coagulant concentration.

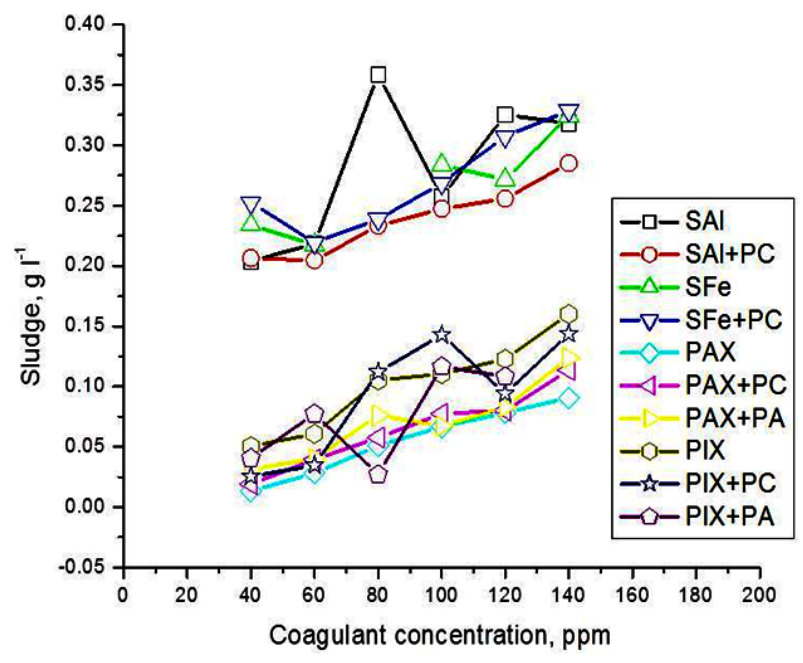

Figure 4. Dry sludge produced at jar tests as function of coagulant concentration.

than the one for SFe which register similar amounts with and without $\mathrm{CP}$. The polychloride PAX produced similar sludge quantities, in which the presence or absence of polymer does not make a great difference. The PIX polychloride produced similar amounts of sludge except at the $80 \mathrm{ppm}$ coagulant in presence of AP, which produced the lower amount of sludge.

Considering the data from SST $\left(\mathrm{cm}^{3} \cdot \mathrm{l}^{-1}\right)$ and sludge mass $\left(\mathrm{g} \cdot \mathrm{l}^{-1}\right)$ it was estimated the sludge density in $\mathrm{g} \mathrm{cm}^{-3}$, results are presented in Figure 5 for the sulfate group, and in Figure $\mathbf{6}$ for the polychlorides group.

As it can be observed in Figure 5 the higher sludge density was obtained with the lower coagulant concentration, use of $\mathrm{Sal}+\mathrm{CP}$ enable to raise sludge density in about $50 \%$, while at higher concentration sludge density increase is not higher to $30 \%$. Otherwise, SFe exhibit similar amounts of sludge with or without $\mathrm{CP}$ at any co-

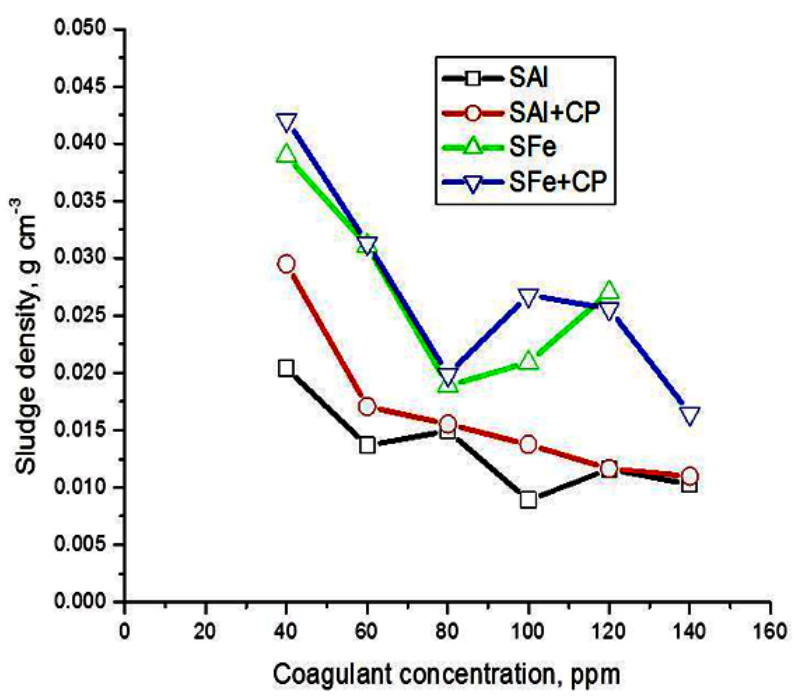

Figure 5. Estimated sludge density from jar tests using SAl and SFe coagulants.

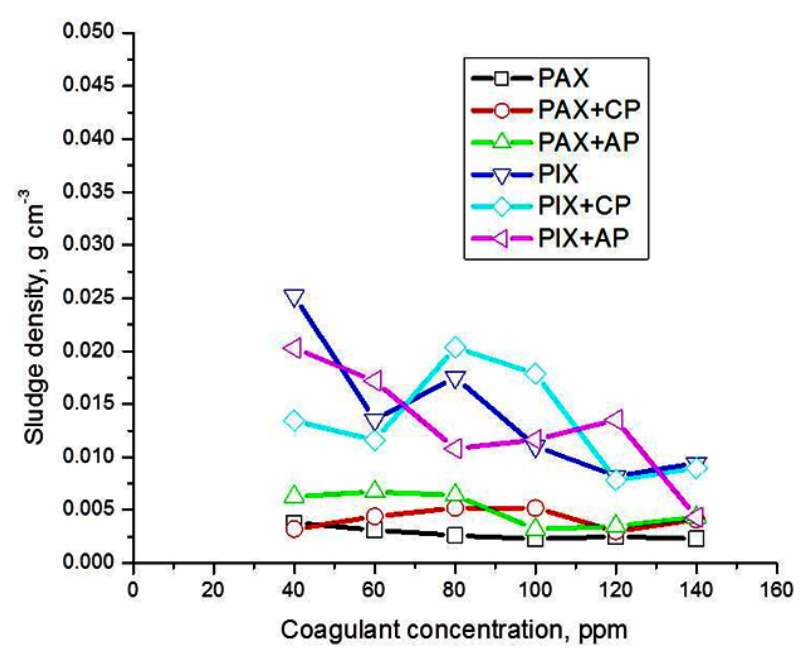

Figure 6. Estimated sludge density from jar tests using PAX and PIX coagulants.

agulant concentration, except for the $100 \mathrm{ppm}$ in which density increases due to the $\mathrm{CP}$ presence.

In Figure 6 it is shown the data for the polychloride coagulants. As it can be observed the sludge density is minimal for the PAX, and addition of CP or AP does not make a great difference in sludge density, obtained values are not greater than $0.005 \mathrm{~g} \cdot \mathrm{cm}^{-3}$ for most coagulant concentrations. Otherwise, the PIX coagulant exhibit higher density than PAX, and for this coagulant the polymer makes a difference since PIX $+\mathrm{CP}$ is the combination which provides the lower density at concentrations of 40 and $60 \mathrm{ppm}$; but for 80 and $100 \mathrm{ppm}$ these concentrations produced a higher sludge density.

\section{Conclusions}

From conductivity measures it can be affirmed that SAl 
and PIX are the coagulants producing a higher salinity condition which should affect sludge dewaterability.

Obtained dry sludge amount is higher when sulfates are used as coagulants either with or without flocculant presence. Also it is observed that $\mathrm{Sal}+\mathrm{CP}$ produced lower SST volumes than SAl, and so far higher density sludge was obtained. Otherwise, in respect to SAl, SFe produced a lower conductivity condition, and lower SST volumes but calculated sludge density resulted greater than the one obtained for SAl.

From polychlorides data, it can be seem that PAX exhibited an almost uniform conductivity for all coagulant concentrations, and produced higher SST volumes than PIX; also dry sludge was less than the one obtained with PIX; in consequence, calculated sludge density for PAX was lower than the one obtained with PIX.

In general, estimated sludge densities were higher at low coagulant dosages. Also, the higher sludge density corresponds to the sulfates group, since observed range is between $0.01-0.045 \mathrm{~g} \cdot \mathrm{cm}^{-3}$; the medium range belongs to PIX since sludge density is between 0.01 and 0.025 $\mathrm{g} \cdot \mathrm{cm}^{-3}$; finally, the lower density belongs to PAX whose values are in the range of 0.002 and $0.007 \mathrm{~g} \cdot \mathrm{cm}^{-3}$.

\section{REFERENCES}

[1] P. A. Vesilind, "Wastewater Treatment Plant Design," Water Environment Federation US, 2003.

[2] W. P. Freese, "Influence of Wastewater Treatment on Sludge Production and Processing," Water and Environment Journal, 2013, pp. 1-10 (in Press).

[3] I. M. C. Lo, K. C. K. Lai and G. H. Chen, "Salinity Effect on Mechanical Dewatering of Sludge with and without Chemical Conditioning," Environmental Science \& Technology, Vol. 35, No. 23, 2001, pp. 4691-4696. doi:10.1021/es010834x

[4] D. Kalderis, M. Aivalioti and E. Gidarakos, "Options for Sustainable Sewage Sludge Management in Small Wastewater Treatment Plant on Islands: The Case of Crete," Desalination, Vol. 260, No. 1-3, 2010, pp. 211-217. doi:10.1016/j.desal.2010.04.030 